\title{
A tot a day keeps disease away
}

\author{
By Michael L. Burr, MRC Epidemiology Unit, 4 Richmond Road, Cardiff CF2 $3 A S$
}

\section{The evidence}

In view of the direct and indirect hazards of alcohol ingestion it hardly seems appropriate to recommend alcohol in the interests of health. Yet there is a substantial body of evidence to support the hypothesis that a small intake of alcohol confers some protection against ischaemic heart disease (IHD).

The geographical evidence, while inevitably imprecise, is remarkably strong and consistent. There is a marked inverse relation between IHD mortality and the consumption of alcohol, particularly in the form of wine (St Leger $e t$ al. 1979). While we cannot be certain that this relation is causal, it provides some encouragement for more detailed studies to be conducted.

Cross-sectional surveys allow us to compare the alcohol intake of individuals with certain physiological variates known to be relevant to IHD. This type of evidence suggests that alcohol has a favourable effect on some factors and an unfavourable effect on others. High-density-lipoprotein (HDL) cholesterol is inversely associated with risk of IHD, and several surveys have revealed a positive association with alcohol intake (Hulley \& Gordon, 1981; Fehily et al. 1982; Yarnell et al. 1982). Blood pressure, on the other hand, shows an unfavourable (positive) association with alcohol in most surveys (Elliott et al. 1987) although it has recently been suggested that this is not the case with wine (Brenn, 1986).

These associations can be tested by means of randomized controlled trials. Three controlled trials have shown that alcohol tends to raise blood pressure (Howes, 1985; Puddey et al. 1985,1987$)$, but the amounts used $(27-80 \mathrm{~g} / \mathrm{d})$ were substantially more than would be supplied by 'a tot a day" (about $9 \mathrm{~g}$ ). Several experimental studies suggest that alcohol has a favourable effect on HDL-cholesterol; two (Hulley \& Gordon, 1981; Thornton et al. 1983) were non-randomized, while two were randomized controlled trials. In one of these (Haskell et al. 1984) the effect was apparently confined to the $\mathrm{HDL}_{3}$ subfraction, which may not be relevant to the risk of IHD, but in the larger study alcohol appeared to raise the $\mathrm{HDL}_{2}$ subfraction, which is inversely associated with $\mathrm{IHD}$ risk (Burr et al. 1986).

It is, of course, impossible to reason directly from an effect on biochemical variates to an effect on mortality. Unfortunately it is not feasible to conduct a randomized trial of alcohol on mortality. The best available evidence relating alcohol consumption and IHD comes from cohort studies in which subjects are followed up to see whether their alcohol intake predicts their disease experience. Numerous such studies have been performed, and are summarized in Table 1. The interpretation of these studies is complicated by differences in design, some being simple prospective studies whereas others involve a case-control analysis of data collected prospectively. Some of the larger cohorts have been analysed more than once. The end-points (incidence, IHD mortality, total mortality, etc.) are not the same in all studies, or are defined in slightly different ways. At the risk of considerable oversimplification, the following points can briefly be made about each.

The Alameda County study (Camacho et al. 1987) showed no relation between alcohol and IHD mortality; total mortality was J-shaped, though significant differences existed 
Table 1. Cohort studies of alcohol and mortality

\begin{tabular}{|c|c|c|c|c|}
\hline \multirow[b]{2}{*}{ Study } & \multirow{2}{*}{$\begin{array}{l}\text { No. in } \\
\text { cohort }\end{array}$} & \multirow[b]{2}{*}{ Sex } & \multicolumn{2}{|c|}{ Relation with alcohol: } \\
\hline & & & IHD & Total mortality \\
\hline Alameda County & 6928 & $8+9$ & None* & J-shape? \\
\hline Albany & 1910 & $\delta$ & Inverse (one study)* & U-shape (two studies) \\
\hline Busselton & 2209 & $8+8$ & Inverse* & Inverse \\
\hline Chicago Western & & & & \\
\hline Electric & 1899 & $\delta$ & J-shape* & Positive at high intake \\
\hline Framingham & 4747 & $\delta+9$ & Inverse in ment & $\begin{array}{l}\text { U-shape in men, none } \\
\text { in women }\end{array}$ \\
\hline Honolulu & 8006 & $\delta$ & Inverse $\dagger$ & Positive? \\
\hline Kaiser-Permanente & 80514 & $\delta+9$ & $\begin{array}{l}\text { Inverse (MI)* } \\
\text { U-shape (chronic IHD)* } \\
\text { Inverse at low intake }\end{array}$ & J-shape \\
\hline London busmen & 687 & 3 & Nonet & - \\
\hline Malmö & 7725 & 3 & - & J-shape? \\
\hline North Karelia & 4063 & $\delta$ & $\begin{array}{l}30-49 \text { years of age, none* } \\
50-59 \text { years of age, inverse* }\end{array}$ & $\begin{array}{l}30-49 \text { years of age, positive } \\
50-59 \text { years of age, inverse? }\end{array}$ \\
\hline Puerto Rico & 9150 & $\delta$ & $\begin{array}{l}\text { U-shape }{ }^{\dagger} \\
\text { J-shape } \\
\text { Inverse* }\end{array}$ & U-shape \\
\hline Regional Heart & 7729 & $\delta$ & None* & - \\
\hline Walnut Creek & 16759 & 9 & Inverse $†$ & - \\
\hline Whitehall & 1422 & $\delta$ & Inverse at low intake* & U-shape \\
\hline Yugoslavia & 11121 & $\delta$ & Inverset & None \\
\hline
\end{tabular}

only between light and very heavy male drinkers. Differences in mortality between abstainers and ex-drinkers were not consistent or statistically significant.

Two successive follow-up analyses of the Albany survey both suggested a U-shaped relation with total mortality, one showing an inverse relation with IHD mortality (Gordon \& Doyle, 1987).

Alcohol intake was not quantified in the Busselton survey (Australia), in which drinkers had a lower IHD and total mortality than non-drinkers (Cullen et al. 1982).

In the Chicago Western Electric study, IHD mortality was J-shaped in relation to alcohol, the lowest point of the J corresponding to an intake of four to five drinks daily. Former drinkers had the highest IHD mortality of all. Total mortality showed little relation with alcohol except for a steep rise in those taking six or more drinks daily; there was also a high mortality in the ex-drinkers (Dyer et al. 1981).

A subset of men in the Framingham survey showed an inverse relation between alcohol and IHD incidence (Gordon et al. 1981). In the whole cohort there was a $\mathrm{U}$-shaped relation between alcohol and total mortality in men, and no relation in women (Gordon \& Kannel, 1984).

An inverse relation with IHD incidence also appeared in the Honolulu study. Men who died tended to have drunk more than had survivors; the difference was significant for all causes other than IHD but not for total mortality (Gordon et al. 1981; McGee et al. 1984).

The Kaiser-Permanente study was based on a very large cohort, within which a 
number of case-control studies have been performed. Alcohol appeared to be inversely related to myocardial infarction (MI) mortality and to have a U-shaped relation with chronic IHD mortality. Non-drinkers seemed to have an increased risk of hospitalization for coronary disease compared with drinkers; the amount drunk was unimportant. A $\mathrm{J}$-shaped relation was found with regard to total mortality (Klatsky et al. 1981a,b).

The study of London busmen and bank workers revealed no relation between alcohol intake and incident of coronary disease; mortality was not specifically examined (Morris et al. 1977). It is difficult to draw firm conclusions from this study: the number of new cases of IHD (47) was probably too small for an effect to be excluded, and in any case the authors apparently only examined linear associations so that a $\mathrm{J}$ - or $\mathrm{U}$-shaped relation would not have been detected.

A case-control study of eighty-two men who died in the Malmö cohort suggested a $\mathrm{J}$-shaped relation between alcohol intake and total mortality (Petersson et al. 1982). The investigators considered that the increased death-rate of the total abstainers may have been due to chronic diseases which prompted the men concerned to give up drinking alcohol. But this conclusion was based on absurdly small numbers: 'Of the seven abstainers in our study who died prematurely, four had organic diseases that might motivate abstinence'.

A larger case-control analysis, involving 223 deaths, was carried out within the North Karelia cohort study (Salonen et al. 1983). Among men aged 30-49 years, alcohol was unrelated to coronary mortality and positively related to total mortality. In men aged 50-59 years, alcohol was negatively related to coronary mortality (significantly) and to total mortality (non-significantly). Consumption of spirits tended to have been lower in men who died of coronary disease and in men who suffered a non-fatal MI.

The Puerto Rico study has been analysed in several alternative ways. Alcohol intake had a U-shaped relation with MI incidence plus coronary death, and also with total mortality; a J-shaped relation appeared when incident heart disease was defined in a different way (angina, non-fatal MI, non-sudden coronary death), and an inverse association with non-sudden coronary death existed when the older and poorer subjects were excluded (Garcia-Palmieri et al. 1980; Gordon et al. 1981; Kittner et al. 1983).

A recent report of the Regional Heart Study (Shaper et al. 1987) examined the relation between alcohol and IHD events, defined as MI (fatal or non-fatal) plus sudden cardiac death. Although the light daily drinkers (one to two drinks daily) had the lowest rates, the differences between them and other groups were not significant, and they had the most favourable characteristics in regard of smoking, blood pressure, body mass and social class. The authors concluded that, compared with other risk factors, alcohol is unimportant in the development of IHD. It must be recognized, however, that a study of this kind was most unlikely to reveal any effect of alcohol. The survey covered twenty-four towns which were selected so as to embrace the widest possible range of IHD mortality in Britain. The factors determining differences between areas may well be different from factors operating within areas; the studies which suggest a protective effect of alcohol have all been based on more homogeneous populations.

The Walnut Creek study involved a large cohort of women who were followed-up primarily in respect of their contraceptive history. A study within this cohort of twenty-six MI cases, matched with numerous controls, showed an inverse relation with alcohol intake (Petitti et al. 1979).

The Whitehall study was based on a cohort of male civil servants in London (Marmot et al. 1981). IHD mortality was highest in total abstainers, with no obvious dose-response relation among drinkers; total mortality showed a U-shaped curve in relation to alcohol intake. 
In the Yugoslavia cardiovascular disease study, alcohol intake was inversely associated with IHD mortality and morbidity but was unrelated to total mortality and sudden death (Kozararevic et al. 1980, 1982). This population was characterized by heavy drinking overall, few of the subjects being absolute non-drinkers, so that the study does not address the hypothesis that moderate or light drinkers have a lower mortality than total abstainers.

Case-control studies in which the alcohol intake has been ascertained retrospectively yield less reliable evidence than do prospective studies. Past alcohol intake is less accurately reported than present intake; patients (or their widows) may be affected by biases different from those affecting healthy controls; and studies of patients who survived MI necessarily exclude fatal cases in which the role of alcohol may be different from that in non-fatal disease. Such studies are therefore not reviewed here.

\section{Interpretation}

A moderate alcohol intake is thus associated fairly consistently with a reduction in IHD mortality and morbidity. But is this association causal? Alternative explanations can be summarized as follows:

(1) Alcohol intake has been inaccurately recorded, since people do not know how much they drink. But (a) inaccuracies will tend to obscure associations, not create them; (b) in some studies (e.g. Fehily et al. 1982) alcohol intake has been measured and recorded as it was taken.

(2) People notoriously lie about their alcohol consumption. But it is difficult to see why people destined to acquire heart disease and those more fortunate should have differential patterns of lying.

(3) Ill-health may lead people to abstain from alcohol. But (a) this effect is as likely to lead to a reduction in intake as to total abstinence, converting some unhealthy heavy drinkers into light and moderate drinkers; (b) there is no obvious reason why a tendency to give up alcohol on health grounds should be specifically characteristic of IHD patients rather than others.

(4) The reason that drinkers don't get IHD is that alcohol kills them off in other ways. But the cohort studies suggest that total mortality is not increased by drinking alcohol until large amounts are imbibed; low intakes appear to have a favourable effect on risk of dying.

(5) The apparently protective effect of alcohol is attributable to confounding variables which can never be entirely eliminated in observational studies. But (a) all the obvious risk factors have been taken into account in most of the analyses; (b) most potentially confounding factors would work against the hypothesis, since total abstainers tend to be more health-conscious than drinkers; (c) it is most unlikely that confounding factors would operate in the same way in the wide variety of countries and circumstances which show such a consistent relation between alcohol and mortality; (d) the randomized controlled trial of alcohol on HDL-cholesterol (Burr et al. 1986) eliminated confounding variables.

\section{Implications}

If alcohol were not abused-if there were no such thing as alcoholism or drunkenness -we would readily accept the evidence that small amounts protect against IHD and recommend a daily drink as a major preventive measure for our most common cause of death. But in fact it is abused, and we cannot predict who is at risk of its serious dangers. 
Occasional binges have other hazards not necessarily reflected in mortality results. Our inability to recommend it is attributable not to the properties of alcohol but to the properties of human nature. A tot a day probably does keep disease away-as long as it doesn't rise to two tots or more. It is probably wise to have alcohol-free days fairly often so as to avoid dependence. But St Paul's advice to 'use a little wine' (1 Tim 5:23) on health grounds still seems to be valid.

\section{REFERENCES}

Brenn, T. (1986). Journal of Epidemiology and Coummunity Health 40, 249-256.

Burr, M. L., Fehily, A. M., Butland, B. K., Bolton, C. H. \& Eastham, R. D. (1986). British Journal of Nutrition 56, 81-86.

Camacho, T. C., Kaplan, G. A. \& Cohen, R. D. (1987). Journal of Chronic Diseases 40, 229-236.

Cullen, K., Stenhouse, N. S. \& Wearne, K. L. (1982). International Journal of Epidemiology 11, 67-70.

Dyer, A. R., Stamler, J., Paul, O., Berkson, D. M., Shekelle, R. B., Lepper, M. H., McKean, H., Lindberg, H. A., Garside, D. \& Tokich, T. (1981). Circulation 64, III.20-III.27.

Elliott, P., Fehily, A. M., Sweetnam, P. M. \& Yarnell, J. W. G. (1987). Journal of Epidemiology and Community Health 41, 37-43.

Fehily, A. M., Milbank, J. E., Yamell, J. W. G., Hayes, T. M., Kubiki, A. J. \& Eastham, R. D. (1982). American Journal of Clinical Nutrition 36, 890-896.

Garcia-Paimieri, M. R., Sorlie, P., Tillotson, J., Costas, R., Cordero, E. \& Rodriquez, M. (1980). American Journal of Clinical Nutrition 33, 1818-1827.

Gordon, T. \& Doyle, J. T. (1987). American Journal of Epidemiology 125, 263-270.

Gordon, T., Kagan, A., Garcia-Palmieri, M., Kannel, W. B., Zukel, W. J., Tillotson, J., Sorlie, P. \& Hjortland, M. (1981). Circulation 63, 500-515.

Gordon, T. \& Kannel, W. B. (1984). American Journal of Epidemiology 120, 97-107.

Haskell, W. L., Camargo, C., Williams, P. T., Vranizan, K. M., Krauss, R. M., Lindgren, F. T. \& Wood, P. D. (1984). New England Journal of Medicine 310, 805-810.

Howes, L. G. (1985). Lancet il, 835.

Hulley, S. B. \& Gordon, S. (1981). Circulation 64, III.57-III.63.

Kittner, S. J., Garcia-Palmieri, M. R., Costas, R., Cruz-Vidal, M., Abbot, R. D. \& Havlik, R. J. (1983). American Journal of Epidemiology 117, 538-550.

Klatsky, A. L., Friedman, G. D. \& Siegelaub, A. B. (1981a). Annals of Intemat Medicine 95, 139-145.

Klatsky, A. L., Friedman, G. D. \& Siegelaub, A. B. (1981b). Circulation 64, III.32-III.41.

Kozararevic, D., Demirovic, J., Gordon, T., Kaelber, C. T., McGee, D. \& Zukel, W. J. (1982). American Journal of Epidemiology 116, 748-758.

Kozararevic, D., McGee, D., Vojvodic, N., Racic, Z., Dawber, T., Gordon, T. \& Zukel, W. (1980). Lancet I, 613-616.

McGee, D. L., Reed, D. M., Yano, K., Kagan, A. \& Tillotson, J. (1984). American Journal of Epidemiology $119,667-676$.

Marmot, M. G., Rose, G., Shipley, M. J. \& Thomas, B. J. (1981). Lancet i, 580-583.

Morris, J. N., Marr, J. W. \& Clayton, D. G. (1977). British Medical Journal if, 1307-1314.

Petersson, B., Trell, E. \& Kristenson, H. (1982). British Medical Journal 285, 1457-1459.

Petitti, D. B., Wingerd, J., Pellegrin, F. \& Ramcharan, S. (1979). Journal of the American Medical Association 242, 1150-1154.

Puddey, I. B., Beilin, L. J. \& Vandongen, R. (1987). Lancet i, 647-651.

Puddey, I. B., Vandongen, R. \& Beilin, L. J. (1985). Lancet $\sharp 1,1119-1120$.

St Leger, A. S., Cochrane, A. L. \& Moore, F. (1979). Lancet I, 1017-1020.

Salonen, J. T., Puska, P. \& Nissinen, A. (1983). Journal of Chronic Diseases 36, 533-543.

Shaper, A. G., Phillips, A. N., Pocock, S. J., \& Walker, M. (1987). British Medical Journal 294, 733-737.

Thornton, J., Symes, C. \& Heaton, K. (1983). Lancet ii, 819-822.

Yarnell, J. W. G., Milbank, J., Walker, C. L., Fehily, A. M. \& Hayes, T. M. (1982). Journal of Epidemiology and Community Health 36, 167-171. 